Relations industrielles

Industrial Relations

\title{
White and Blue-Collars in a Mill Shutdown, par Felician F. Foltman, ILR, Paperback No. 6, Cornell University, Ithaca, New York, 132 pages.
}

\section{Laurent Bélanger}

\section{Volume 24, numéro 3, 1969}

URI : https://id.erudit.org/iderudit/028055ar

DOI : https://doi.org/10.7202/028055ar

Aller au sommaire du numéro

\section{Éditeur(s)}

Département des relations industrielles de l'Université Laval

ISSN

0034-379X (imprimé)

1703-8138 (numérique)

Découvrir la revue

Citer ce compte rendu

Bélanger, L. (1969). Compte rendu de [White and Blue-Collars in a Mill

Shutdown, par Felician F. Foltman, ILR, Paperback No. 6, Cornell University,

Ithaca, New York, 132 pages.] Relations industrielles / Industrial Relations, 24(3),

641-641. https://doi.org/10.7202/028055ar

Tous droits réservés (C Département des relations industrielles de l'Université Laval, 1969
Ce document est protégé par la loi sur le droit d'auteur. L'utilisation des services d’Érudit (y compris la reproduction) est assujettie à sa politique d'utilisation que vous pouvez consulter en ligne.

https://apropos.erudit.org/fr/usagers/politique-dutilisation/ 
White and Blue-Collars in a Mill Shutdown, par Felician F. Foltman, ILR, Paperback No. 6, Cornell University, Ithaca, New York, 132 pages.

Au cours des deux dernières décades, plusieurs travaux de recherche s'attaquèrent à l'étude des problèmes auxquels font face les travailleurs devant la perte possible de leur emploi par suite de l'introduction de changements technologiques. On a appris, par exemple, que l'âge, l'ancienneté, la spécialisation sont autant de facteurs qui influencent les possibilités pour un travailleur déplacé de se trouver un nouvel emploi. En étudiant les réactions et attitudes des travailleurs face à un licenciement éventuel, ont aussi appris que les colletsbleus sont beaucoup plus attachés à leur communauté et lieu de résidence que les collets-blancs.

En vue de mieux comprendre le comportement des travailleurs, dans ces circonstances, l'auteur de cette plaquette formule au début de son étude une proposition assez audacieuse : les colletsblancs déplacés par un changement technologique afficheraient un comportement beaucoup plus « rationnel » que les collets-bleus, dans la recherche d'un nouvel emploi. Le concept de rationalité utilisé dans cette étude a une signification particulière: celle que lui a donné Henry Simon dans ses volumes et articles traitant des limites de la rationalité dans la prise de décision.

Dans les termes empruntés de Simon, les collets-blancs, dans leur recherche d'un nouvel emploi, seraient des « maximizers » i.e. qu'ils accepteraient un autre emploi après avoir longuement pesé les avantages et les inconvénients. Leur choix serait le produit d'un calcul économique, alors que les collets-bleus seraient plutôt des «satisfiers》 i.e. qu'ils se contenteraient du premier emploi qu'on leur offrirait.

Pour vérifier son hypothèse de départ, Foltman a expédié une série de questionnaires à 1455 employés de la région de Buffalo sans emploi après la fermeture de l'usine Wickwire de la Colorado Fuel and Iron Corporation. On a retourné 505 copies du questionnaire dont $72 \%$ remplies par des collets-bleus et $28 \%$ par des collets-blancs. Les données ainsi recueillies apportent un certain fondement à l'hypothèse de travail for- mulée au début. Les collets-blancs seraient beaucoup plus astucieux et feraient preuve d'un esprit plus calculateur que les collets-bleus dans leur quête d'un nouvel emploi.

En plus de décrire ainsi le comportement des deux catégories de travailleurs sur un marché du travail local, l'auteur a recueilli des données additionnelles sur les réactions et attitudes respectives des collets-bleus et collets-blancs face à la fermeture de l'usine de Wickwire.

On peut difficilement généraliser des proportions que l'on formule à la suite d'une étude d'un ou plusieurs cas de fermeture d'usine. Cependant, ce n'est pas une raison pour abandonner l'effort de recherche dans ce domaine. La comparaison des résultats peut servir à ceux qui sont impliqués dans la formulation des politiques de main-d'oeuvre.

\section{Laurent BELANGER}

The Mission of Manpower Policy, par E. Wight Bakke, The W.E. Upjohn Institute for Employment Research, Michigan, April 1969, 126 pp.

Selon l'auteur, le public en général et les autorités concernées, se font une fausse idée politique de main-d'oeuvre. $\mathrm{Ce}$ dernier considère le maintien du plein emploi comme un objectif louable mais insuffisant.

Concernant les programmes actuels, il se pose un certain nombre de questions sur leur coût, leurs résultats, etc... Jusqu'à date les programmes de maind'oeuvre ont consisté surtout en un système complexe d'assistance publique, alors qu'une véritable politique de maind'oeuvre devra dépasser ce stade et s'attacher aux problemes de tous les citoyens et non plus seulement à ceux qui sont propres au groupe des «désavantagés 》.

Même si en Europe on favorise davantage les mesures macro-économiques, i.e. les politiques fiscales et monétaires, il n'en résulte pas moins un certain nombre de problèmes, comme par exemple, un risque accrû d'inflation dans les secteurs déjà progressifs. Aussi doit-on prévoir d'autres mesures qui vont venir corriger les inconvénients d'une politique au niveau de l'économie globale. 